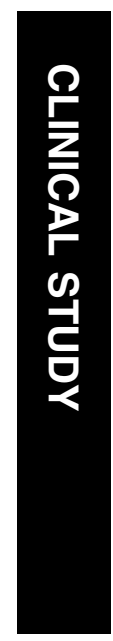

\title{
Prevalence and associations of epiretinal membranes in adult Chinese: the Beijing eye study
}

${ }^{1}$ Beijing Institute of Ophthalmology, Beijing Tongren Hospital, Capital University of Medical Sciences, Beijing, China

${ }^{2}$ Department of Ophthalmology, Medical Faculty Mannheim of the Ruprecht-Karls-University of Heidelberg, Mannheim, Germany

Correspondence: $\mathrm{L} X \mathrm{X}$ and JB Jonas,

Beijing Institute of Ophthalmology,

17 Hougou Street, Chong Wen Men, Beijing 100005, China

Tel: + 49621383 2652;

Fax: + 496213833803

E-mail: Jost.Jonas@

augen.ma.uni-heidelberg.de

Received: 13 October 2006 Accepted in revised form: 16 February 2007 Published online: 23 March 2007

Proprietary interest: None

\begin{abstract}
Purpose To determine the prevalence of epiretinal membranes in the adult Chinese population.

Methods The Beijing Eye Study, a population-based, cross-sectional cohort study, included 4439 subjects out of 5324 subjects invited to participate (response rate $83.4 \%$ ) with an age of $40+$ years. The present investigation consisted of $4378(\mathbf{9 8 . 6 \%})$ subjects for whom readable fundus photographs $(30$ nonstereoscopic colour images) were available. Assessing the fundus photographs, we differentiated two membrane types: cellophane maculopathy and premacular fibrosis. Results Prevalence rate of epiretinal membranes was $2.2 \pm 0.2 \%$ (mean $\pm \mathrm{SE}$ ) $(\mathbf{9 5 \%}$ confidence interval $(\mathrm{CI}): \mathbf{1 . 9 , 2 . 5 )}$ per eye or $2.2 \pm 0.2 \%(95 \%$ CI: $1.8,2.7)$ per subject. In binary logistic regression analysis, the prevalence of epiretinal membranes was significantly associated with age $(P<0.001$; 95\% CI: 1.07,1.12), visual field loss $(P<0.001$; 95\% CI: $1.03,1.07)$, hyperopia $(P=0.02 ; 95 \%$ CI: 1.01,1.18), and higher education $(P<0.001$; 95\% CI: 1.29,1.74). Cellophane maculopathy showed a prevalence rate of $1.11 \pm 0.1 \%(95 \%$ CI: $0.9,1.3)$ per eye and $1.8 \pm 0.2 \%(95 \%$ CI: 1.4,2.2) per subject. Its prevalence was significantly associated with age $(P<0.001$; 95\% CI: 1.08,1.13), higher education $(P<0.001$; 95\% CI: 1.26,1.92), and visual field loss $(P=0.009 ; 95 \%$ CI: 1.01,1.07). Premacular fibrosis had a prevalence rate of $1.06 \pm 0.1 \%$ (95\% CI: $0.9,1.3)$ per eye and $1.8 \pm 0.2 \%(95 \%$ CI: 1.4,2.2) per subject. It was significantly associated with age $(P<0.001 ; 95 \% \mathrm{CI}$ : 1.06,1.11), higher level of education $(P<0.001$; 95\% CI: 1.15,1.74), and visual field loss $(P=0.001 ; 95 \%$ CI: $1.02,1.08)$.
\end{abstract}

Q You ${ }^{1}, L X u^{1}$ and JB Jonas ${ }^{1,2}$

Conclusion In adult Chinese in Greater Beijing, epiretinal membranes including cellophane maculopathy and premacular fibrosis occur in a relatively low frequency which may be lower than in Western countries. Epiretinal membranes including its subtypes of cellophane maculopathy and epiretinal fibrosis were associated with age and hyperopic refractive error.

Eye (2008) 22, 874-879; doi:10.1038/sj.eye.6702786; published online 23 March 2007

Keywords: epiretinal membrane; cellophane maculopathy; epiretinal macular fibrosis; pars plana vitrectomy; visual acuity; Beijing eye study

Introduction

Epiretinal membranes on the inner surface of the macula are detected in eyes after intraocular interventions such as cataract surgery, retinal detachment repair, retinal laser and retinal cryopexie, and they are found independent of preceding procedures in eyes without any other detected abnormalities. ${ }^{1-7}$ They may be caused by the migration of cells through small defects in the internal limiting membrane. ${ }^{8}$ These cells proliferate and form a thin veil of tissue at the inner retinal-vitreous interface. Electron microscopy has shown glial cells, retinal pigment epithelium cells, fibrocytes, myofibroblasts, and fibrous astrocytes to be involved. ${ }^{9}$ Epiretinal membranes have clinically and ultrastructurally been differentiated into an early form and late form. The early type caused by purely glial cells is sometimes called cellophane maculopathy or cellophane macular reflex and is clinically usually asymptomatic. In 
the late type of epiretinal membranes, a prominent fibrous, nonglial component has been demonstrated in membranes causing traction and wrinkling of the retina. ${ }^{10}$ The late form is usually more severe than the early form and is also called preretinal macular fibrosis or macular pucker. Owing to the traction and wrinkling of the retina, it can cause significant loss in central visual acuity and distortions in the paracentral visual acuity such as metamorphopsias. In severe situations, cystoid macular oedema may develop as shown in fluorescein angiography. ${ }^{11}$

Despite their clinical significance, there have been, besides a series of hospital-based studies, only six population-based investigations on the occurrence and associations of epiretinal membranes with other ocular and general parameters. ${ }^{12-17}$ All these epidemiological studies were focused on whites, Hispanics or Japanese. Considering that China is the largest nation and that information about epiretinal membranes in the Chinese population is very scarce, it was the purpose of the present study to assess the prevalence of epiretinal membranes and their associations with ocular and general factors in Chinese as part of the Beijing Eye Study.

\section{Methods}

The Beijing Eye Study is a population-based prospective cohort study in Northern China. It included in total 4439 subjects (8878 eyes; 2505 women) out of 5324 subjects invited to participate, corresponding to a response rate of $83.4 \%$. The study was divided into a rural part (3946 eyes, 1973 subjects; 1143 women) and an urban part (4932 eyes, 2466 subjects; 1362 women). Mean age was $56.20 \pm 10.59$ years (median, 56 years; range, 40-101 years). The Medical Ethics Committee of the Beijing Tongren Hospital had approved the study protocol and all participants had given informed consent, according to the Declaration of Helsinki. The study has been described in detail recently. ${ }^{18-23}$ After getting an informed consent, a detailed ophthalmic examination was carried out including measurement of uncorrected and best corrected visual acuity (Snellen charts), noncontact tonometry (CT-60 computerized tonometer, Topcon Ltd, Japan), frequency doubling perimetry using the screening programme C-20-1 (Zeiss-Humphrey, Dublin, California, USA), slit lamp examination of the anterior segment, ophthalmoscopy, and photography of the lens (Neitz CT-R camera; Neitz Instruments Co., Tokyo, Japan) and of the fundus (fundus camera, type CR6-45NM, Canon Inc., Tokyo, Japan) after medical mydriasis. Past history of eye diseases, eye trauma, diabetes mellitus, hypertension, and any ophthalmologic care the participant received were recorded.
Using the fundus photographs, the occurrence of epiretinal membranes was assessed. Two types of epiretinal membranes were differentiated as described by Klein et al. and Fraser-Bell and colleagues: ${ }^{12,16}$ The first type consisted of a cellophane macular reflex only with a patch or patches of irregular increased reflection from the inner retinal surface. In the second type called premacular fibrosis, a greyish and opaque appearance of the inner retinal surface was combined with superficial retinal folds or traction lines. If both types of epiretinal membranes were detected, the eye was allocated to the most severe, second type. In addition, the epiretinal membranes were subdivided into primary membranes, if no reason for the development of membranes became evident; and into secondary membranes found in eyes with retinal vein occlusions, retinal detachment, diabetic retinopathy, and cataract surgery. All photographs were examined and graded by a trained reader (QY). In case of doubt, a panel of ophthalmologists (QSY, JBJ, LX) re-assessed the diagnosis and grading.

In addition, the optic disc photographs were examined for the presence of glaucomatous optic nerve damage as described in detail recently. ${ }^{21,24,25}$ The optic disc slides were projected and we examined the qualitative parameters 'shape of the neuroretinal rim' with special respect to the inferior-superior-nasal-temporal (ISNT) rule including the presence of neuroretinal rim notches, occurrence of optic disc haemorrhages, presence of localized defects in the retinal nerve fibre layer, decreased diffuse visibility of the retinal nerve fibre layer, and occurrence of marked diffuse thinning or focal thinning of the retinal arteries in the peripapillary region. The optic disc photographs were additionally digitized and the optic disc structures were measured by outlining the borders of the optic disc, optic cup, peripapillary scleral ring, and $\alpha$ zone and $\beta$ zone of peripapillary atrophy border on the computer screen. To examine the relationship between epiretinal membranes and glaucoma, two different glaucoma definitions were applied. ${ }^{20}$ In the definition of 'Optic Disc Glaucoma', the only criterion for glaucoma was a glaucomatous appearance of the optic disc. ${ }^{21}$ In the definition of 'Perimetric Glaucoma', the optic disc appeared glaucomatous and the visual field showed defects that could be explained by no other disease than glaucomatous optic neuropathy. A visual field defect was defined as any abnormal test point in the frequency doubling perimetry if the rate of false-positive results was equal to, or lower, than 0.33 , and if the rate of fixation loss was equal to, or lower, than 0.33. Intraocular pressure was no criterion for the diagnosis.

For the evaluation of the retinal vascular abnormalities, focal narrowing of arterioles, generalized narrowing of arterioles, sheathing of arterioles, and 
arteriovenous crossing abnormalities (arteriovenous nicking) were assessed. The colour optic disc photographs of one randomly selected eye of each subject were morphometrically examined using the assessment protocol of the Atherosclerosis Risk in Communities (ARIC) study. ${ }^{26}$

Using the slit lamp photographs of the lens, the degree of nuclear cataract, cortical cataract, and subcapsular cataract was graded using the classifying scheme for cataract of the Age-Related Eye Disease Study. ${ }^{27,28}$

For study purposes, we diagnosed diabetes mellitus by a self-reported history of physician diagnosis or those who were on drug treatment for diabetes (insulin or oral hypoglycaemic agents). Arterial hypertension was defined as a self-reported history of physician diagnosis or subjects who were receiving drug treatment for hypertension. Coronary artery disease was diagnosed based on a history of documented myocardial infarction and/or drug treatment for coronary heart disease (aspirin or nitrates). Additionally, individuals were classified as self-reported non-smokers or self-reported current smokers.

Statistical analysis was performed by using a commercially available statistical software package (SPSS for Windows, version 13.0, SPSS, Chicago, IL, USA). The prevalences of epiretinal membranes were calculated as percentages of the total population. Logistic regression was used to investigate the associations of the binary dependent variable 'presence of epiretinal membranes' with the continuous or categorical independent variables, such as age, gender, education level, and intraocular pressure. Odds ratios (OR) and 95\% confidence intervals (CI) were calculated to describe the influence of age, gender, area, and education degree to the prevalence of epiretinal membranes.

\section{Results}

Out of the 4439 subjects included in the study, fundus photographs with sufficient quality for examination were available for 8662 eyes of 4378 participants $(98.6 \%$ of the original sample). The mean age was $56.0 \pm 10.4$ years, ranging from 40 to 101 years, and the mean refractive error was $-0.32 \pm 2.11$ dioptres (D), ranging from -20.9 to +7.88 D). For 216 (2.4\%) eyes, fundus photographs could not be examined because either photographs were not taken $(n=129 ; 1.5 \%)$ or because available photographs could not be assessed owing to lens opacities or vitreous clouding $(n=87 ; 1.0 \%)$. For the eyes not included in the analysis, the subjects were significantly older $(66.6 \pm 11.2$ years $v s 56.0 \pm 10.5$ years; $P<0.001$; 95\% CI: 9.12, 12.14), were significantly more myopic $(-1.32 \pm 3.9 \mathrm{D}$ vs $-0.33 \pm 2.11 \mathrm{D} ; P=0.002 ; 95 \%$ CI: $-1.61,-0.37)$, had lower best corrected visual acuity
$(0.57 \pm 0.37$ vs $0.91 \pm 0.21 ; P<0.001 ; 95 \% \mathrm{CI}:-0.39,-0.29)$, and more marked nuclear cataract $(3.6 \pm 1.5$ grade $v$ s $2.5 \pm 1.1$ grade; $P<0.001 ; 95 \%$ CI: $0.93,1.39)$, cortical cataract $(0.12 \pm 0.23$ vs $0.01 \pm 0.06 ; P<0.001 ; 95 \%$ CI: 0.07 , $0.15)$, and subcapsular cataract $(0.05 \pm 0.16$ vs $0.002 \pm 0.03$; $P=0.001 ; 95 \%$ CI: $0.02,0.08$ ). Both groups did not vary significantly in intraocular pressure $(15.6 \pm 3.4$ vs $16.1 \pm 3.4 \mathrm{~mm} \mathrm{Hg} ; P=0.06$; 95\% CI: $-0.95,0.01)$.

An epiretinal membrane was detected in 188 (2.2\%) eyes (prevalence rate (mean $\pm \mathrm{SE}$ ): $2.2 \pm 0.2 \%$; $95 \%$ CI: 1.9 , $2.5)$ of $97(2.2 \%)$ subjects (prevalence rate: $2.2 \pm 0.2 \%$; $95 \%$ CI: $1.8,2.7)$. Mean age of all patients with epiretinal membranes was $56.1 \pm 10.5$ years (median, 56.0 years; range, 40-101 years), mean refractive error was $-0.37 \pm 2.21 \mathrm{D}$ (median, $0.00 \mathrm{D}$; range, -20.13 to +7.50 D). After stratifying the total study population into hyperopic eyes (hyperopic refractive error (spherical equivalent) $>0.50 \mathrm{D}$ ), emmetropic eyes (refractive error $\leqslant+0.50 \mathrm{D}$ and $\geqslant-0.50 \mathrm{D}$ ), and myopic eyes (myopic refractive error $\geqslant-0.50 \mathrm{D})$, prevalence of an epiretinal membrane was $3.2 \pm 0.4 \%$ (95\% CI: $2.3,4.0)$ in the hyperopic group, $1.8 \pm 1.9 \%(95 \% \mathrm{CI}: 1.4,2.1)$ in the emmetropic group, and $2.2 \pm 3.4 \%$ (95\% CI: $1.5,2.8)$ in the myopic group.

If in a bivariate analysis the subjects with epiretinal membranes were compared with the subjects without epiretinal membranes, the prevalence of epiretinal membranes was significantly associated with age $(P<0.001 ; 95 \%$ CI: $-10.6,-8.3)$, visual field loss $(P<0.001 ; 95 \%$ CI: $-2.60,-0.68)$, low best corrected visual acuity $(P<0.001 ; 95 \% \mathrm{CI}: 0.04,0.11)$, amount of nuclear cataract $(P<0.001 ; 95 \% \mathrm{CI}:-0.88,-0.45)$, hyperopic refractive error $(P=0.008 ; 95 \% \mathrm{CI}:-0.58$, $-0.09)$, higher level of education $(P=0.002 ; 95 \% \mathrm{CI}$ : $-0.40,-0.09)$, self-reported diagnosis of cerebral haemorrhage or infarction $(P<0.001$; OR: 2.78 ; 95\% CI: $1.67,4.68)$ and of coronary heart disease $(P=0.002$; OR: 1.88; 95\% CI: 1.29, 2.73), presence of glaucomatous optic nerve damage ('Optic Disc Glaucoma') $(P<0.001$; OD: 3.12; 95\% CI: 1.78, 5.46), and urban region $(P<0.001$; OR: 3.20; $95 \%$ CI: 2.24, 4.58).

Both groups did not vary significantly in gender $(P=0.71$; OR: $1.06 ; 95 \% \mathrm{CI}: 0.79,1.42)$, intraocular pressure $(P=0.50 ; 95 \% \mathrm{CI}:-0.30,0.62)$, amount of cortical cataract $(P=0.12 ; 95 \% \mathrm{CI}:-0.02,0.01)$, and of subcapsular cataract $(P=0.52 ; 95 \% \mathrm{CI}:-0.01,0.01)$, presence of age-related macular degeneration (early and late stage) ( $P=0.77$; OR: 1.03 ; 95\% CI: $0.32,3.26)$, the degree of arteriovenous kinking in the temporal vessel arcade $(P=0.36 ; 95 \% \mathrm{CI}:-0.39,0.14)$, and in the temporal superior arcade $(P=0.45 ; 95 \% \mathrm{CI}:-0.38,0.17)$, frequency of focal arteriolar narrowing in the temporal inferior arcade $(P=0.13,95 \% \mathrm{CI}:-0.49,0.06)$, the self-reported diagnosis of diabetes mellitus $(P=0.50$; OR: $1.20 ; 95 \%$ CI: 
$0.64,2.23)$, arterial hypertension $(P=0.22$; OR: $1.25 ; 95 \%$ CI: $0.88,1.77)$, and of hyperlipidemia $(P=1.00$; OR: 0.98 ; $95 \%$ CI: $0.67,1.44)$, and the frequency of cataract surgery $(P=0.27$; OR: $1.92 ; 95 \% \mathrm{CI}: 0.6,6.2)$.

In a binary logistic regression analysis, the prevalence of epiretinal membranes was no longer significantly associated with the degree of nuclear cataract $(P=0.23)$, presence of age-related macular degeneration $(P=0.64)$ or glaucomatous optic nerve damage $(P=0.26)$, the selfreported diagnosis of cerebral infarction of haemorrhage $(P=0.69)$, and of coronary heart disease $(P=0.80)$, and urban region $(P=0.19)$. The associations between the presence of epiretinal membranes and age $(P<0.001)$, visual field loss $(P<0.001)$, hyperopic refractive error $(P=0.02)$, and higher level of education $(P<0.001)$ remained statistically significant (Table 1 ).

\section{Cellophane maculopathy}

A cellophane maculopathy was detected in $96(1.11 \%)$ eyes (prevalence rate: $1.11 \pm 0.1 \%$; $95 \% \mathrm{CI}: 0.9,1.3)$ of 78 (1.8\%) subjects (prevalence rate: $1.8 \pm 0.2 \%$; 95\% CI: 1.4 , 2.2). In binary logistic regression analysis, prevalence of cellophane maculopathy was significantly associated with age ( $P<0.001 ; 95 \% \mathrm{CI}: 1.08,1.13)$, higher level of education $(P<0.001 ; 95 \% \mathrm{CI}: 1.26,1.92)$, and visual field loss $(P=0.009 ; 95 \% \mathrm{CI}: 1.01,1.07)$. It was statistically not associated with refractive error $(P=0.19 ; 95 \% \mathrm{CI}$ : 0.97 , 1.19).

\section{Premacular fibrosis}

A premacular fibrosis was detected in $92(1.06 \%)$ eyes (prevalence rate: $1.06 \pm 0.1 \%$; 95\% CI: $0.9,1.3)$ of $81(1.8 \%$ ) subjects (prevalence rate: $1.8 \pm 0.2 \% ; 95 \%$ CI: $1.4,2.2$ ). Prevalence of premacular fibrosis was significantly associated with age $(P<0.001 ; 95 \% \mathrm{CI}: 1.06,1.11)$, higher level of education $(P<0.001 ; 95 \%$ CI: $1.15,1.74)$, visual field loss ( $P=0.001 ; 95 \%$ CI: $1.02,1.08)$, and hyperopic refractive error $(P=0.08$; 95\% CI: $0.99,1.23)$.

\section{Discussion}

The prevalence rate of premacular fibrosis in the Beijing Eye Study (1.06\% per eye and $1.8 \%$ per subject) was similar to the rate found in the Visual Impairment Project in Australia (1.7\%), and it was lower than that found in the Blue Mountain Study (2.2\%), the Los Angeles Latino Eye Study (LALES) (2.2\%), and the Beaver Dam Study $(2.8 \%) .{ }^{12,13,15,17}$ In a more striking manner, the prevalence rate of cellophane maculopathy in the Beijing Eye Study (1.11\% per eye and $1.8 \%$ per subject) was markedly lower than that in the Blue Mountain Study (4.8\%), the Visual Impairment Project in Australia (4.8\%), and particularly lower than in the Beaver Dam Study (9\%) and the LALES Study (16.3\%). ${ }^{12,13,15,17}$ As in the previous studies, the presence of epiretinal membranes was associated with age. In addition, epiretinal membranes were more common in hyperopic eyes. In contrast to preceding hospital- and population-based investigation, the prevalence of epiretinal membranes was not associated with cataract surgery in the Beijing Eye Study.

The reasons why the prevalence rates of epiretinal membranes differ between the Beijing Eye Study and the population-based investigations on Caucasian and Hispanic populations have remained unclear so far. One of the reason may be differences in the definition of cellophane maculopathy and premacular fibrosis as well as differences in the quality of the fundus photographs to detect the epiretinal abnormalities. For the present study, however, the same definition was applied as in the previous investigations, and the quality of the fundus photographs was sufficient in the great majority of subjects to detect subtle abnormalities. It is questionable, therefore, whether the marked differences in the prevalence rates of epiretinal membranes between the studies mentioned was owing to differences in the

Table 1 Results of the logistic regression analysis between presence of epiretinal membranes and ocular and general parameters in the Beijing Eye Study 2001

\begin{tabular}{lcc}
\hline Parameter & P-value & 95\% confidence interval \\
\hline Degree of nuclear cataract & 0.23 & $0.84,1.04$ \\
Age-related macular degeneration & 0.64 & $0.24,2.44$ \\
Glaucomatous optic nerve damage & 0.26 & $0.76,2.78$ \\
Self-reported diagnosis of cerebral infarction of haemorrhage & 0.69 & $0.47,1.65$ \\
Coronary heart disease & 0.80 & $0.53,1.21$ \\
Urban region & 0.19 & $0.85,2.30$ \\
Age & $<0.001$ & $1.07,1.12$ \\
Visual field loss & $<0.001$ & $1.03,1.07$ \\
Hyperopic refractive error & 0.02 & $1.01,1.18$ \\
Higher level of education & $<0.001$ & $1.29,1.74$ \\
\hline
\end{tabular}


examination of the subjects or was because of differences between the population groups examined. Another reason for the discrepancies between the studies may be ethnic differences in the background pigmentation of the fundus leading to differences in the ophthalmoscopic visibility of the epiretinal membranes. Interestingly, the prevalence of diabetic retinopathy and age-related macular degeneration, and their percentage as cause for visual impairment or blindness was markedly lower in the Beijing Eye Study than in the population-based investigations in Western countries. ${ }^{29-36}$

As in the population-based studies, the prevalence of epiretinal membranes was significantly associated with age. In addition, hyperopic refractive error was a factor associated with the frequency of epiretinal membranes in the present study. In contrast to the previous investigations, status after cataract surgery was not correlated with epiretinal membranes. Reason for the differences between the studies may be that the frequency of cataract surgery in the Beijing Eye Study was relatively low $(0.91 \%$ per eye or $1.3 \%$ per subjects) preventing a statistically significant relationship between cataract surgery and detected epiretinal membranes.

In conclusion, epiretinal membrane including cellophane maculopathy, and premacular fibrosis occur in a relatively low frequency in adult Chinese in Greater Beijing. The rate found in the Beijing Eye Study is lower than the prevalence rate reported for Western countries. In adult Chinese in Greater Beijing, epiretinal membranes including its subtypes of cellophane maculopathy and epiretinal fibrosis were associated with age and hyperopic refractive error.

\section{References}

1 Appiah AP, Hirose T. Secondary causes of premacular fibrosis. Ophthalmology 1989; 96: 389-392.

2 Hagler WS, Aturaliya U. Macular puckers after retinal detachment surgery. Br J Ophthalmol 1971; 55: 451-457.

3 Wise GN. Relationship of idiopathic preretinal macular fibrosis to posterior vitreous detachment. Am J Ophthalmol 1975; 79: 358-362.

4 Wiznia RA. Posterior vitreous detachment and idiopathic Preretinal macular gliosis. Am J Ophthalmol 1986; 102: 196-198.

5 Hirokawa H, Jalkh AE, Takahashi M, Takahashi M, Rempe $\mathrm{CL}$, Schepens CL. Role of the vitreous in idiopathic Preretinal macular fibrosis. Am J Ophthalmol 1986; 101: 166-169.

6 Apiah AP, Hirose T, Kado M. A review of 324 cases of idiopathic premacular gliosis. Am J Ophthalmol 1988; 106: 533-535.

7 Kishi S, Shimizu K. Oval defect in detached posterior hyaloid membrane in idiopathic preretinal macular fibrosis. Am J Ophthalmol 1994; 118: 451-456.

8 Margherio RM, Margherio AR. Epiretinal macular membranes. In: Albert DM, Jacobiec FA (eds). Principles and
Practice of Ophthalmology, Vol. 5. WB Saunders Philadelphia, 2000, pp 2103-2110.

9 Smiddy WE, Maguire AM, Green WR, Michels RG, de la Cruz Z, Enger $C$ et al. Idiopathic epiretinal membranes: ultrastructural characteristics and clinicopathologic correlations. Ophthalmology 1989; 96: 811-820.

10 Hiscott PS, Grierson I, Trombetta CJ, Rahi AH, Marshall J, McLeod D. Retinal and epiretinal glia: an immunohistochemical study. Br J Ophthalmol 1984; 68: 698-707.

11 Maguire AM, Margherio RR, Dmuchowski C. Preoperative fluorescein angiographic features of surgically removed idiopathic epiretinal membranes. Retina 1994; 14: 411-416.

12 Klein R, Klein BE, Wang Q, Moss SE. The epidemiology of epiretinal membranes. Trans Am Ophthalmol Soc 1994; 92: 103-125.

13 Mitchell P, Smith W, Chey T, Wang JJ, Chang A. Prevalence and associations of epiretinal membranes. The Blue Mountains Eye Study. Ophthalmology 1997; 104: 1033-1040.

14 Miyataki M, Nakamura H, Kubo M, Kiyohara Y, Tida M, Ishibashi $\mathrm{T}$ et al. Prevalence and risk factors for epiretinal membranes in a Japanese population : the Hisayama study. Graefes Arch Clin Exp Ophthalmol 2003; 241: 642-646.

15 Fraser-Bell S, Guzowski M, Rochtchina E, Wang JJ, Mitchell P. Five-year cumulative incidence and progression of epiretinal membranes. The Blue Mountains Eye Study. Ophthalmology 2003; 110: 34-40.

16 Fraser-Bell S, Ying-Lai M, Klein R, Varma R, Los Angeles Eye Study Group. Prevalence and associations of epiretinal membranes in Latinos: The Los Angeles Latino Eye Study. Invest Ophthalmol Vis Sci 2004; 15: 1732-1736.

17 McCarty DJ, Mukesh BN, Chikani V, Wang JJ, Mitchell P, Taylor HR et al. Prevalence and associations of epiretinal membranes in the visual impairment project. Am J Ophthalmol 2005; 140: 288-294.

18 Xu L, Cui T, Zhang S, Sun B, Zheng Y, Hu A et al. Prevalence and risk factors of lens opacities in urban and rural Chinese in Beijing. Ophthalmology 2006; 113: 747-755.

19 Wang Y, Xu L, Zhang L, Yang H, Ma Y, Jonas JB. Optic disc size in a population-based study in Northern China. The Beijing Eye Study. Br J Ophthalmol 2006; 90: 353-356.

$20 \mathrm{Xu} \mathrm{L}$, Li J, Cui T, Hu A, Fan G, Zhang Ret al. Refractive error in urban and rural adult Chinese in Beijing. Ophthalmology 2005; 112: 1676-1683.

21 Xu L, Wang Y, Wang S, Wang Y, Jonas JB. High myopia and glaucoma susceptibility. The Beijing Eye Study. Ophthalmology 2007; 114: 216-220.

22 Xu L, Wang S, Li Y, Jonas JB. Retinal vascular abnormalities and prevalence of age-related macular degeneration in adult Chinese. The Beijing Eye Study. Am J Ophthalmol 2006; 142: $688-689$.

23 Wang S, Xu L, Jonas JB, Wang YS, Wang Y, Yang H et al. Retinal vascular abnormalities in adult Chinese in rural and urban Beijing. The Beijing Eye Study. Ophthalmology 2006; 142: 688-689.

24 Jonas JB, Budde WM, Panda-Jonas S. Ophthalmoscopic evaluation of the optic nerve head. Surv Ophthalmol 1999; 43: 293-320.

25 Jonas JB, Fernández MC, Naumann GOH. Glaucomatous parapapillary atrophy: Occurrence and correlations. Arch Ophthalmol 1992; 110: 214-222.

26 Klein R, Sharrett AR, Klein BE, Chambless LE, Cooper LS, Hubbard LD et al. Are retinal arteriolar abnormalities related to atherosclerosis?. The Atherosclerosis Risk in Communities Study. Arterioscler Thromb Vasc Biol 2000; 20: 1644-1650. 
27 Age-Related Eye Disease Study Research Group. Risk factors associated with age-related nuclear and cortical cataract: a case-control study in the Age-Related Eye Disease Study. AREDS Report No. 5. Ophthalmology 2001; 108: $1400-1408$.

28 Age-Related Eye Disease Study Research Group. The AgeRelated Eye Disease Study (AREDS) system for classifying cataracts from photographs: AREDS report no. 4. Am J Ophthalmol 2001; 131: 167-175.

29 Xu L, Wang Y, Li Y, Li J, Wang Y, Cui T et al. Causes of blindness and visual impairment in an urban and rural area in Beijing: the Beijing Eye Study. Ophthalmology 2006; 113: 1141.e1-3.

30 Li Y, Xu L, Jonas JB, Yang H, Ma Y, Li J. Prevalence of agerelated maculopathy in adult Chinese. The Beijing Eye Study. Am J Ophthalmol 2006; 142: 788-793.

31 Klein R, Klein BE, Linton KL. Prevalence of age-related maculopathy: the Beaver Dam Eye Study. Ophthalmology 1992; 99: 933-943.
32 Mitchell P, Smith W, Attebo K, Wang JJ. Prevalence of agerelated maculopathy in Australia: the Blue Mountains Eye Study. Ophthalmology 1995; 102: 1450-1460.

33 Vingerling JR, Dielemans I, Hofman A, Grobbee DE, Hijmering M, Kramer CF et al. The prevalence of age-related maculopathy in the Rotterdam Study. Ophthalmology 1995; 102: 205-210.

34 Attebo K, Mitchell P, Smith W. Visual acuity and the causes of visual loss in Australia. The Blue Mountains Eye Study. Ophthalmology 1996; 103: 357-364.

35 Klaver CC, Wolfs RC, Vingerling JR, Hofman A, de Jong PT. Age-specific prevalence and causes of blindness and visual impairment in an older population: the Rotterdam Study. Arch Ophthalmol 1998; 116: 653-658.

36 Ramrattan RS, Wolfs RC, Panda-Jonas S, Jonas JB, Bakker D, Pols HA et al. Prevalence and causes of visual field loss in the elderly and associations with impairment in daily functioning: the Rotterdam Study. Arch Ophthalmol 2001; 119: 1788-1794. 